in vivo $34: 1077-1084(2020)$

doi:10.21873/invivo.11878

\title{
Wogonin Influences Osteosarcoma Stem Cell Stemness Through ROS-dependent Signaling
}

\author{
HYEBIN $\mathrm{KOH}^{1}{ }^{*}, \mathrm{HU}-\mathrm{NAN} \mathrm{SUN}^{2 *}, \mathrm{ZHEN} \mathrm{XING}{ }^{3}$, REN LIU ${ }^{3}$, \\ NISANSALA CHANDIMALI ${ }^{3}$, TAEHO KWON ${ }^{4}$ and DONG-SUN LEE ${ }^{3,5,6,7}$ \\ ${ }^{1}$ Department of Animal Biotechnology, Jeju National University, Jeju, Republic of Korea; \\ ${ }^{2}$ College of Life Science and Biotechnology, Heilongjiang Bayi Agricultural University, Daqing, P.R. China; \\ ${ }^{3}$ Interdisciplinary Graduate Program in Advanced Convergence Technology and Science, \\ Jeju National University, Jeju, Republic of Korea; \\ ${ }^{4}$ Primate Resources Center, Korea Research Institute of Bioscience and Biotechnology, Jeonbuk, Republic of Korea; \\ ${ }^{5}$ Subtropical/Tropical Organism Gene Bank, Jeju National University, Jeju, Republic of Korea; \\ ${ }^{6}$ Faculty of Biotechnology, College of Applied Life Sciences, Jeju National University, Jeju, Republic of Korea; \\ ${ }^{7}$ Practical Translational Research Center, Jeju National University, Jeju, Republic of Korea
}

\begin{abstract}
Backgorund/Aim: Wogonin, a flavonoid-like compound extracted from the root of Scutellaria baicalensis Georgi, has been shown to have anticancer effects against cancer cells. Osteosarcoma is the most malignant type of bone cancer and can appear in any bone, with a high propensity for relapse and metastasis. The present study aimed to assess the anticancer effects of wogonin on osteosarcoma stem cells. Materials and Methods: The cytotoxic effects of wogonin on $\mathrm{CD} 133^{+}$Cal72 osteosarcoma stem cells were assessed through in vitro experiments by MTT assay, transwell assay, sphere-formation assay, flow cytometry, immunocytochemistry and western blotting. Results: Wogonin suppressed stem cell characteristics and the expression of stem cell-related genes by regulating reactive oxygen species (ROS) levels and ROS-related signaling of $\mathrm{CD} 33^{+}$Cal72 cells, effects which were reversed by ROS scavenger $N$-acetylcysteine. Conclusion: Wogonin may be a promising candidate for successful clinical management of osteosarcoma by regulating ROSrelated mechanisms and stem cell-related genes.
\end{abstract}

This article is freely accessible online.

*These Authors contributed equally to this study.

Correspondence to: Professor Dong-Sun Lee, Department of Biotechnology, College of Applied Life Science, Jeju National University, Jeju, Republic of Korea. Tel: +82 647543340, e-mail: dongsunlee@jejunu.ac.kr

Key Words: Wogonin, osteosarcoma, cancer stem cells, ROS, stemness.
Osteosarcoma, the most common type of malignant bone tumor, is most prevalent among children and adolescents and accounts for $2.4 \%$ of pediatric cancer cases (1). It is most common among the ages of 10-16 years and the second most common among those aged over 40 years. The tumor is potentially present in bone marrow and then may grow into a mass of tumors and can occur in any bone (2). At present, the first-line treatment for most osteosarcoma involves surgery with intensive adjuvant chemotherapy (3). However, many patients still have poor survival due to relapse and metastasis of osteosarcoma (4).

Cancer stem cells (CSCs) are cancer cells that have characteristics related to stem cells, such as self-renewal and differentiation abilities (5). Expression of CSC genes is known to induce cancer metastasis (6). In particular, it was reported that osteosarcoma stem cells have a high capacity for tumor metastasis (2). A pentaspan membrane glycoprotein, CD133, is one of the most well-known biomarkers used for the detection of CSCs. It plays an important role in tumor growth, metastasis, tumorigenesis and tumor relapse (7). Finding a drug candidate involved in down-regulating the expression of genes related to osteosarcoma stem cell behaviour is an urgent need.

Reactive oxygen species (ROS) are forms of active oxygen and result from cellular metabolism (8). Some studies have revealed that an increased ROS level reduces the expression of stemness-related genes in CSCs and this effect can be reversed by ROS scavengers such as $\mathrm{N}$ acetylcysteine (NAC) $(9,10)$.

Wogonin (5,7-dihydroxy-8-methoxyflavone) is a flavonoid-like compound that extracted from the root of Scutellaria baicalensis Georgi (Figure 1A) (11). It is wellknown for diverse biological effects such as anti- 
inflammatory, antioxidant and anticancer effects o various cell types such as non-small cell lung cancer, prostate cancer and ovarian cancer. Furthermore, according to some recent studies, wogonin may be a candidate anticancer drug, with the virtue of inducing selective apoptosis in cancer cells (12). Recently, we showed that wogonin has inhibitory effects on metastasis of cancer by down-regulating the expression of matrix metallopeptidase 9 in osteosarcoma stem cell (13). However, the regulatory mechanism underlying the effects of wogonin on osteosarcoma stem cell stemness is not yet understood.

In this study, we observed the effects of wogonin on the stemness of osteosarcoma stem cells and investigated the possible mechanisms involved in $\mathrm{CD}_{13} 3^{+} \mathrm{Cal} 72$ cells.

\section{Materials and Methods}

Reagents. Wogonin (98\% of purity by high-performance liquid chromatography) was purchased from Sigma-Aldrich (St. Louis, MO, USA), dissolved in dimethyl sulfoxide (DMSO) and stored at $-20^{\circ} \mathrm{C}$.

Cell culture and treatments. $\mathrm{CD}_{133^{+}} \mathrm{Cal}^{2} 2$ cells (Gibco, ThermoFisher Scientific, Waltham, MA, USA) were cultured in Dulbecco's modified Eagle's medium (DMEM; Invitrogen, Carlsbad, CA, USA) containing $10 \%$ fetal bovine serum (FBS; Hyclone, Logan, UT, USA) and $1 \%$ penicillin (Invitrogen) supplemented with $10 \mathrm{ng} / \mathrm{ml}$ human epidermal growth factor (hEGF; Calbiochem, Kenilworth, NJ, USA) and $20 \mathrm{ng} / \mathrm{ml}$ basic fibroblast growth factor (bFGF; KOMA Biotech, Seoul, Republic of Korea). The cells were maintained in an incubator at $37^{\circ} \mathrm{C}$ with $5 \%$ $\mathrm{CO}_{2}$. In further experiments, $\mathrm{CD} 133^{+} \mathrm{Cal} 72$ cells were pre-treated for $1 \mathrm{~h}$ with $5 \mu \mathrm{M} \mathrm{N}$-acetylcysteine (NAC) (Sigma, St. Louis, MO, USA) prior to exposure to $0,20,40$ and $80 \mu \mathrm{M}$ wogonin for $24 \mathrm{~h}$.

3-(4,5-Dimethylthiazol-2-yl)-2,5-diphenyltetrazolium bromide (MTT) for cytotoxicity and cell proliferation assay. $\mathrm{CD} 133+\mathrm{Cal} 72$ cells were seeded at a density of $1 \times 10^{4}$ cells/well in 96-well plates and incubated for $24 \mathrm{~h}$ before treatment. Cells were treated with wogonin with or without pre-treatment with $5 \mu \mathrm{M} \mathrm{NAC}$ for $1 \mathrm{~h}$ in DMEM containing 1\% FBS for cytotoxicity assay, or 10\% FBS for $24 \mathrm{~h}$ for cell proliferation assay. EZ-Cytox (Dogenbio, Seoul, Republic of Korea) was added to each well, and the plates were incubated for $1 \mathrm{~h}$ at $37^{\circ} \mathrm{C}$. The optical density (OD) was then measured using a scanning multi-well spectrophotometer at a wavelength of $450 \mathrm{~nm}$.

Western blotting. Lysates from $\mathrm{CD}_{133}{ }^{+} \mathrm{Ca} 172$ cells treated with wogonin with or without NAC were collected in RIPA buffer (150 $\mathrm{mM} \mathrm{NaCl}, 1 \%$ Nonidet p- $40,50 \mathrm{mM}$ Tris, $\mathrm{pH} 8.0$, and a protease inhibitor cocktail). From each sample, $30 \mu \mathrm{g}$ was loaded on a gel for sodium dodecyl sulfate-polyacrylamide gel electrophoresis and run in 1x Tris Glycine (T\&I, Chuncheon, Republic of Korea). The proteins were transferred onto a nitrocellulose membrane (Bio-Rad, Hercules, CA, USA). Western blot was performed with rabbit or mouse antibodies against survivin (Abcam, Cambridge, MA, USA), CD133 (Boster Bio, Pleasanton, CA, USA), octamer-binding transcription factor 3/4 (OCT3/4) (Santa Cruz Biotechnology, Dallas, TX, USA), protein kinase B (AKT) phospho-AKT (p-AKT), extracellular signal-regulated kinase (ERK), p-ERK, signal transducer and activator of transcription 3 (STAT3), p-STAT3, peroxiredoxin 2 (PRX2), PRX3, PRX5 (AbFrontier, Seoul, Republic of Korea), NOTCH1 (Cell Signaling Technology, Danvers, MA, USA), and MYC (Bioss, Woburn, MA, USA). Specific binding was detected using a Super Signal chemiluminescent substrate (ThermoFisher Scientific), according to the manufacturer's instructions.

Immunocytochemistry assay for stemness marker CD133. CD133+ Cal72 cells were seeded at a density of $5 \times 10^{4}$ cells/well in 4 -well plates in growth medium and treated with wogonin $(0,20,40,80$ $\mu \mathrm{M})$ for $24 \mathrm{~h}$. The cells were fixed in $3.7 \%$ paraformaldehyde for $10 \mathrm{~min}$ and incubated in blocking solution $(1 \%$ bovine serum albumin) for $1 \mathrm{~h}$ at room temperature. The cells were incubated with primary antibodies against CD133 diluted in blocking buffer overnight at $4{ }^{\circ} \mathrm{C}$ and then stained by a fluorescent secondary antibody, goat anti-rabbit IgG (Santa Cruz Biotechnology) with phycoerythrin for $2 \mathrm{~h}$ at room temperature. Nuclei were stained for 15 min with 2-(4-amidinophenyl)- $1 H$-indole-6-carboxamidine. Images were captured under an inverted microscope (14).

ROS detection with 2',7'-dichlorofluorescin diacetate (DCF-DA). $\mathrm{CD} 133^{+} \mathrm{Cal} 72$ cells were seeded in 6-well plates in growth medium and treated with wogonin $(0,20,40,80 \mu \mathrm{M})$ with or without $5 \mathrm{mM}$ NAC. After $24 \mathrm{~h}$, cells were incubated with $20 \mu \mathrm{M}$ DCF-DA in a dish at $37^{\circ} \mathrm{C}$ for $20 \mathrm{~min}$ then fluorescence imaging and flow cytometry (BD Biosciences, San Jose, CA, USA) were performed $(10,14)$.

Sphere-formation assay. $\mathrm{CD} 133^{+} \mathrm{Cal} 72$ cells were seeded at $2 \times 10^{3}$ cells/well in 6-well Ultra Low Cluster plates (Corning, New York City, NY, USA). The cells were cultured with DMEM/F12 (Invitrogen) containing 2\% B27 supplement (Invitrogen), $10 \mathrm{ng} / \mathrm{ml}$ hEGF, $20 \mathrm{ng} / \mathrm{ml}$ basic fibroblast growth factor (bFGF), and $1 \%$ antibiotics, and treated with wogonin $(0,20,40,80 \mu \mathrm{M})$ with or without $5 \mathrm{mM}$ NAC for 7 days $(10,14)$. The size of spheres was estimated under a microscope.

Wound-healing assay. $\mathrm{CD} 133^{+} \mathrm{Cal} 72$ cells were seeded at $5 \times 10^{4}$ cells/well in 96-well and allowed to grow to 98-100\% confluence. Using a wound maker (Essen Bioscience, Ann Arbor, MI, USA), a linear scratch was made in the cell layer $(10,14)$. Cells were washed with $1 \mathrm{X}$ phosphate-buffered saline and DMEM containing wogonin $(0,20,40,80 \mu \mathrm{M})$ and $0.5 \%$ FBS was added. Photomicrographs were taken of the migrated cells at 0 and $24 \mathrm{~h}$ using the IncuCyte Live-Cell Analysis System (Essen Bioscience).

Transwell migration and Matrigel invasion assays. In vitro migration and invasion assays were performed using transwell 24well chambers (pore size $8 \mu \mathrm{m}$; Merck Millipore, Darmstadt, Germany) without (migration) or with (invasion) Matrigel. Briefly, $150 \mu \mathrm{l}$ of CD133+ Cal72 cell suspensions $\left(1 \times 10^{5}\right.$ cells/well) were treated with wogonin $(0,20,40,80 \mu \mathrm{M})$ in DMEM containing $0.5 \%$ FBS and seeded separately into the upper chambers; the lower chamber well contained $750 \mu \mathrm{l}$ of DMEM with $20 \%$ FBS. Cells were then incubated for $48 \mathrm{~h}$ at $37^{\circ} \mathrm{C}$ and with $5 \% \mathrm{CO}_{2}$. Noninvading cells were then removed from the upper chamber, while invading cells were fixed with $3.7 \%$ paraformaldehyde and stained with $0.1 \%$ crystal violet. The cell count was performed under a microscope $(10,14)$. 
A<smiles>COc1c(O)cc(O)c2c(=O)cc(-c3ccccc3)oc12</smiles>

C

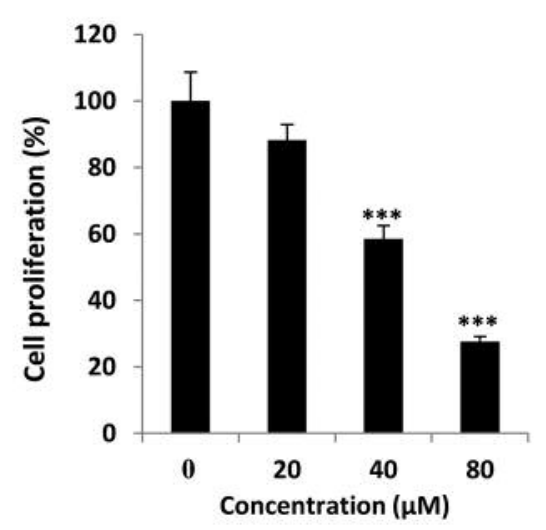

B

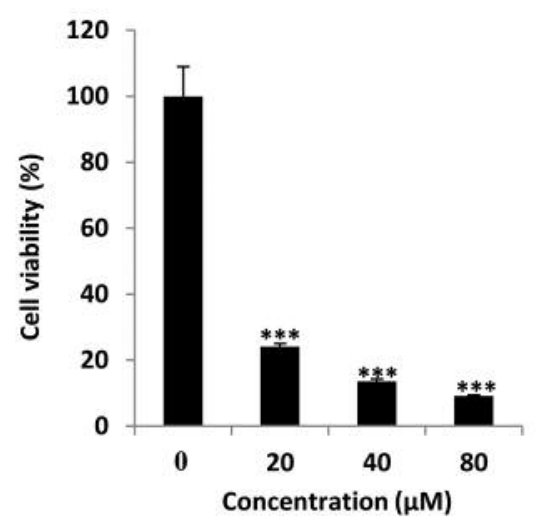

D

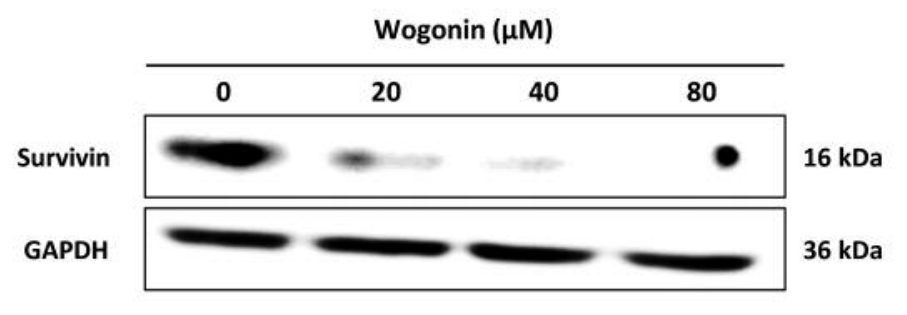

Figure 1. The effect of wogonin on CD133+ Cal72 cell viability and proliferation. Assays revealed a dose-dependent reduction of viability of wogonintreated CD133+ Cal72 cells. A. Two-dimensional structure of wogonin. B: Cytotoxicity assay. C: Cell proliferation. D: Western blotting showed dosedependent reduction of survivin expression as on inhibitor of apoptotic activation. ${ }^{* *}$ Significantly different from control cells at $p<0.001$.

Data analysis. Statistical analyses were performed using SPSSv.20.0.1 software (IBM, Armonk, NY, USA). Experimental differences among treatment groups with values of $p<0.05$ were considered statistically significant for the cell viability assay.

\section{Results}

Wogonin reduced cell viability and proliferation of $\mathrm{CD} 133^{+}$ Cal72 cells. To confirm the cytotoxic effects of wogonin, cytotoxicity and proliferation MTT assays were performed after wogonin treatment $(0,20,40,80 \mu \mathrm{M})$ of $\mathrm{CD} 133^{+} \mathrm{Cal} 72$ cells. The results showed that wogonin treatment significantly reduced cell viability (Figure 1B) and inhibited $\mathrm{CD} 133^{+}$Cal72 cell growth (Figure 1C). Furthermore, western blotting showed that wogonin treatment significantly down-regulated the protein expression of survivin, which is inhibitor of apoptotic activation (Figure 1D). These data indicate that wogonin was cytotoxic and suppressed cell proliferation of $\mathrm{CD}_{133^{+}}$Cal72 cells most likely by inducing cell death.
Wogonin reduced the stemness, migration, and self-renewal ability of $\mathrm{CD}_{133^{+}} \mathrm{Cal72}$ cell. To determine whether wogonin affected the self-renewal ability of $\mathrm{CD}_{133^{+} \mathrm{Cal} 72}$ cells, sphere-formation assays were performed. As shown in Figure 2A, the size of spheres was reduced in a dosedependent manner, indicating that self-renewal of $\mathrm{CD} 133^{+}$ Cal72 cells was inhibited by wogonin treatment. Woundhealing assay revealed that wogonin suppressed metastasis as observed by the lower restoral of scratches (Figure 2B). Transwell assays showed that wogonin treatment also reduced the migratory and invasive capacities of $\mathrm{CD}_{133}{ }^{+}$ Cal72 cells (Figure 2C and D).

Furthermore, the expression of several cancer stem cell markers was assessed after wogonin treatment. The results showed that stem cell markers CD133 and OCT3/4 were significantly down-regulated by wogonin treatment in a dosedependent manner (Figure 2E). The down-regulation of CD133 expression was also confirmed by immunocytochemistry. The results revealed that wogonin dramatically reduced the expression of CD133 compared to control cells (Figure 2F). 
A
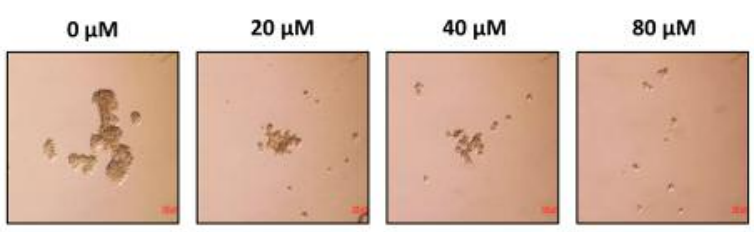

B

B $\quad 0 \mu \mathrm{M}$
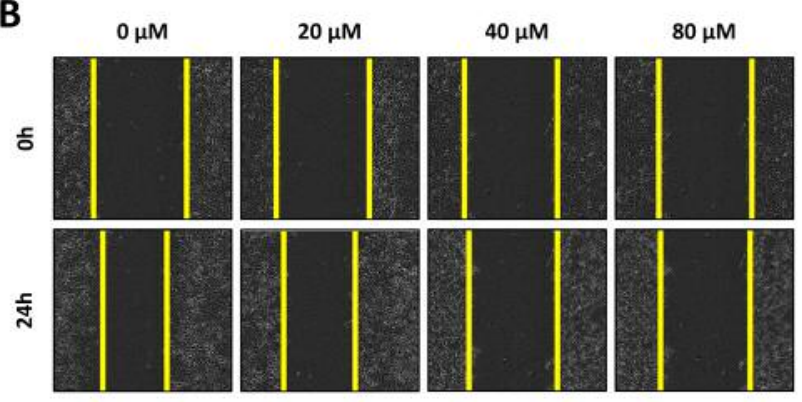

E

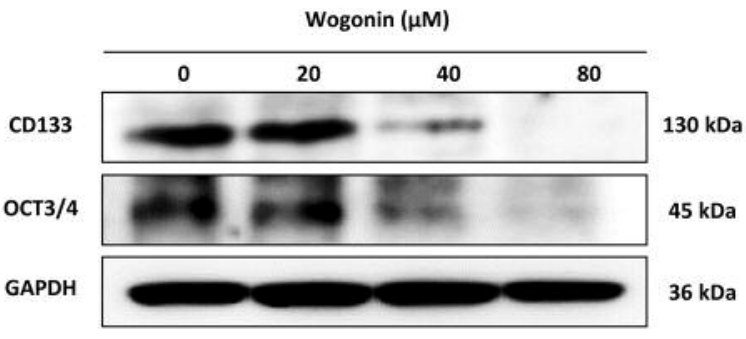

C
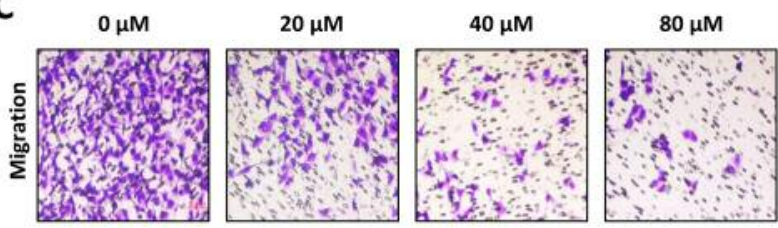

D
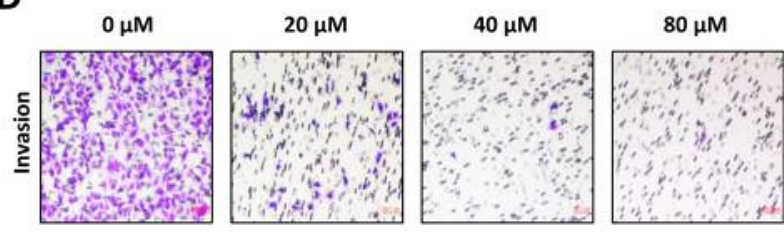

F

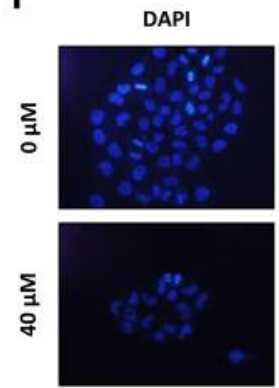

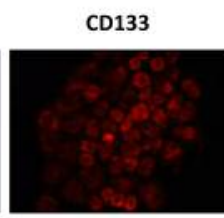
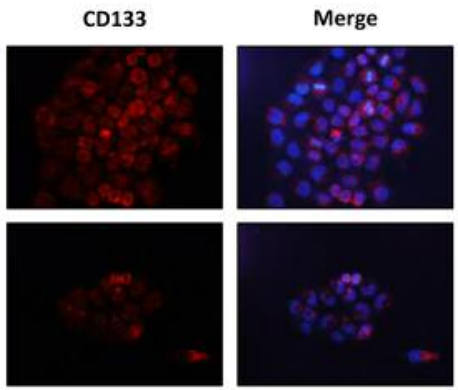

Figure 2. Inhibition of $C D 133^{+}$Cal72 showed dose-dependent effects on cell stemness, migration, and self-renewal ability by wogonin treatment. A: Sphere-formation assay of wogonin on self-renewal. B: Wound-healing assay. C: Transwell migration. D: Transwell invasion assay. E: Western blotting showed dose-dependent reduction of gene expression related to cancer stem cells. F: Immunocytochemistry assay showed 40 $\mu M$ wogonin suppressed CD133 expression of CD133+ Cal72 cells. GAPDH: glyceraldehyde 3-phosphate dehydrogenase; OCT3/4: octamer-binding transcription factor 3/4.

Taken together, these findings show that wogonin suppressed $\mathrm{CD} 133^{+}$Cal72 cell stemness by inhibiting cell migration, invasion and sphere formation, as well as the expression of cancer stem cell surface markers.

Effect of wogonin on cellular ROS level and ROS-dependent signaling in $\mathrm{CD} 133^{+}$Cal72 cells. To clarify the effect of wogonin on cellular ROS level and signaling related to ROS, $\mathrm{CD}_{133}{ }^{+} \mathrm{Cal} 72$ cells were treated with wogonin $(0,20,40$ and $80 \mu \mathrm{M})$. The cellular ROS level was detected by DCFDA staining and measured by flow cytometry (Figure 3A) and fluorescence microscopy (Figure 3B). The results showed that wogonin treatment significantly increased the cellular ROS level in a dose-dependent manner, being greatest at $80 \mu \mathrm{M}$. Furthermore, we also examined the protein expression level of peroxiredoxins, a family of antioxidant enzymes reported to be essential in scavenging intracellular $\operatorname{ROS}(14,15)$. The results showed that wogonin treatment affected the protein expression of PRX family members, especially by down-regulating PRX5, which can efficiently eliminate ROS in cytosol and mitochondria (16), while not markedly affecting PRX2 and PRX3 in CD133 ${ }^{+}$ Cal72 cells (Figure 3C).

The ROS-dependent signaling pathways (17) were also examined after wogonin treatment. As shown Figure 3D, wogonin treatment significantly inhibited the phosphorylation of AKT and STAT3, as well as NOTCH1 protein expression,

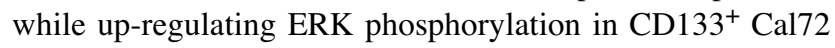
cells. Together, these data suggest that wogonin induces cellular ROS and regulates ROS-dependent signaling in $\mathrm{CD}_{133^{+} \text {Cal72 cells. }}$

ROS was involved in wogonin-induced efforts on stemness in $\mathrm{CD}_{133^{+}}$Cal72 cell. NAC is an efficient cellular ROS scavenger (18). To clarify the effect of ROS on wogonininduced reduction of cell proliferation, CD133 ${ }^{+} \mathrm{Cal} 72$ cells were pre-treated with $5 \mathrm{mM}$ of NAC followed by wogonin treatment. As shown in Figure 4A, NAC pre-treatment significantly abrogated wogonin-induced inhibition of cell proliferation and also reversed the wogonin-induced 


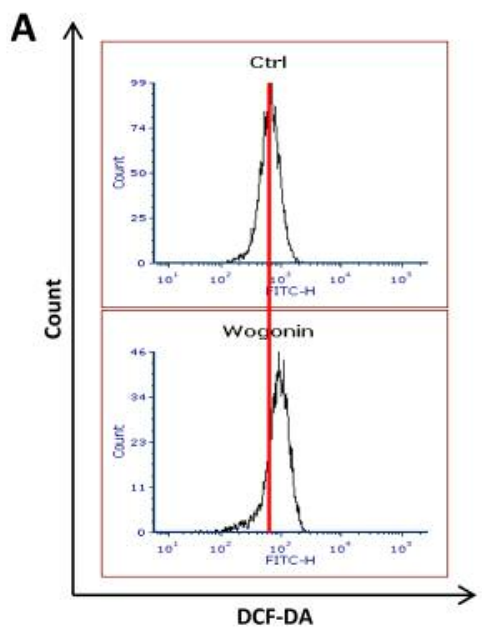

C

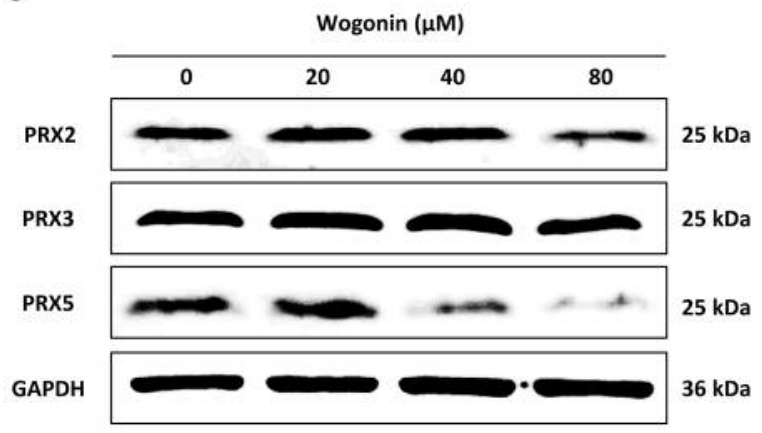

B
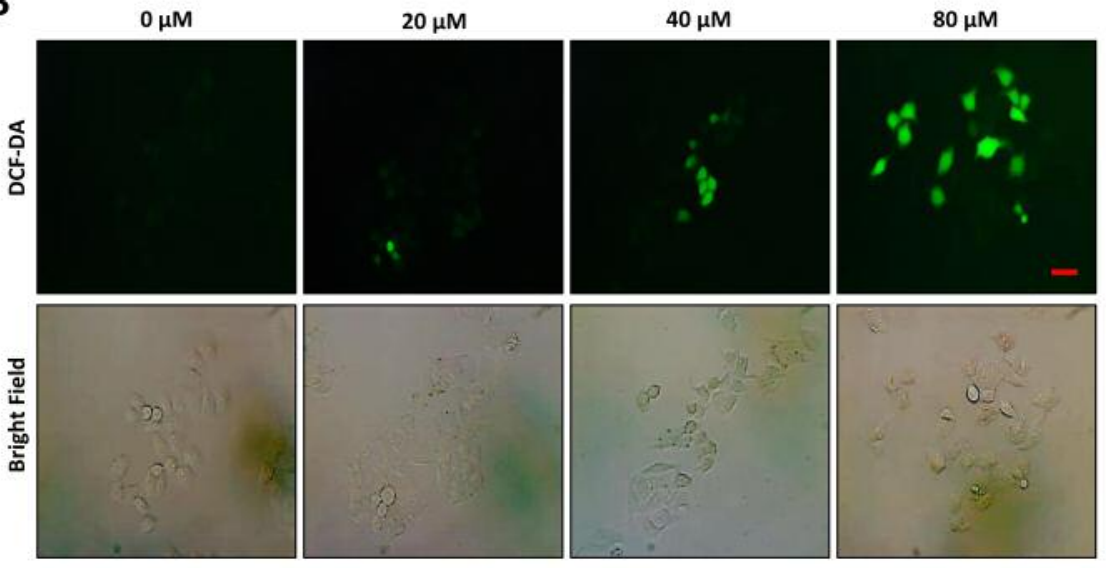

Wogonin $(\mu \mathrm{M})$

D

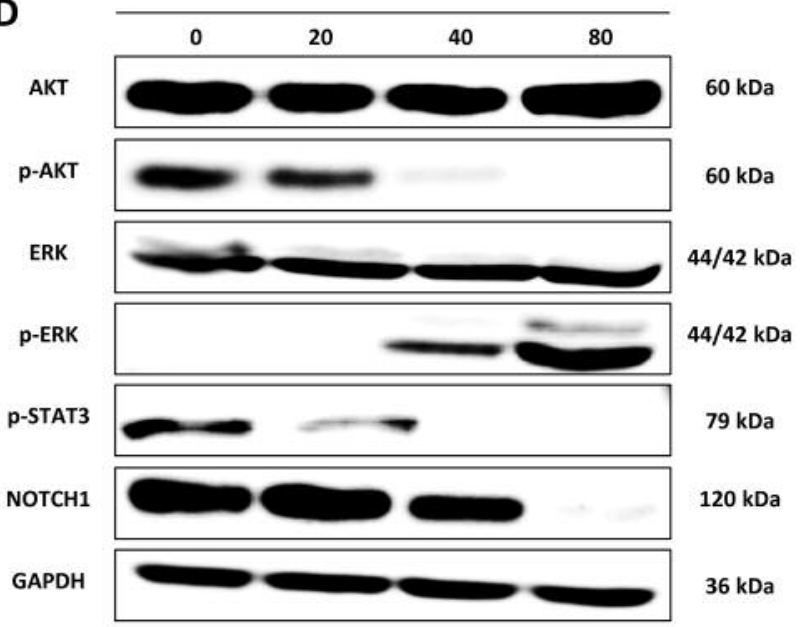

Figure 3. Increase of ROS level in CD133+ Cal72 cells by wogonin. A and B: 2,7-Dichloro-dihydro-fluorescein diacetate (DCF-DA) assays were performed to determine the effect of wogonin on the ROS level. C: The effects of wogonin on the expression of peroxiredoxins PRX2, PRX3 and PRX5 proteins were detected by western blotting. D: The effects of wogonin on proteins involved in reactive oxygen species (ROS)-dependent signaling in $\mathrm{CD} 133^{+}$Cal72 cells were detected by western blotting. AKT: Protein kinase B; p-AKT: phospho-AKT; ERK: extracellular signalregulated kinase; p-ERK: ERK; STAT3: signal transducer and activator of transcription 3, p-STAT3: phospho-STAT3.

accumulation of cellular ROS in CD133+ Cal72 cells (Figure 4B). Furthermore, the effect of NAC treatment on single cell sphere-forming ability was assessed. As shown in Figure 4C, NAC treatment significantly restored sphere-forming ability which was inhibited by wogonin treatment in a dosedependent manner. We also examined the effect of NAC treatment on MYC and STAT3 phosphorylation, which are reported closely related to the maintenance of stem cell stemness. As shown in Figure 4D, NAC treatment dramatically reversed the down-regulation of MYC and STAT3 phosphorylation level induced by wogonin. These data show ROS is associated with the effects of wogonin on stemness in $\mathrm{CD}_{133^{+}}$Cal72 cells. NAC suppression of ROS restored stemness and the ability for self-renewal.

\section{Discussion}

CSC properties have been reported in numerous types of tumors and are considered to be the cause of tumor initiation, selfrenewal, resistance to tumor therapeutics, and metastasis (19). In this study, we describe the cytotoxic activity of wogonin, which is a phytochemical extracted from the root of $S$. baicalensis Georgi. Wogonin may be helpful for patients with osteosarcoma by inducing ROS and osteosarcoma stem cell death. The analysis of in vitro experiments suggests that wogonin increases the ROS level in cells and inhibits stemness by regulating ROS-related signaling in osteosarcoma stem cells.

Peroxiredoxins have the ability to protect sensitive proteins from oxidative damage from ROS (20). PRXs are classified 
A

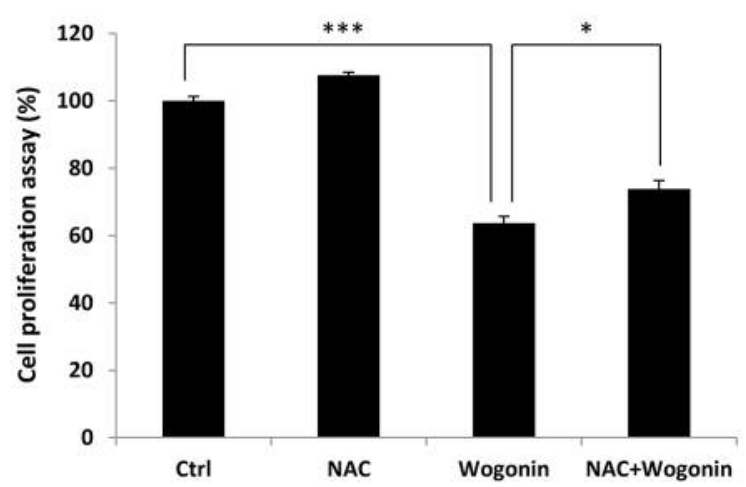

C

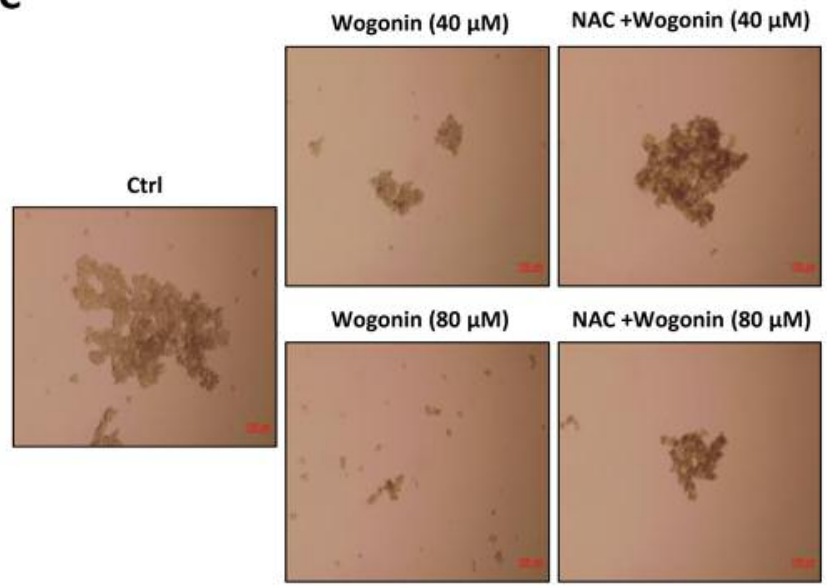

B

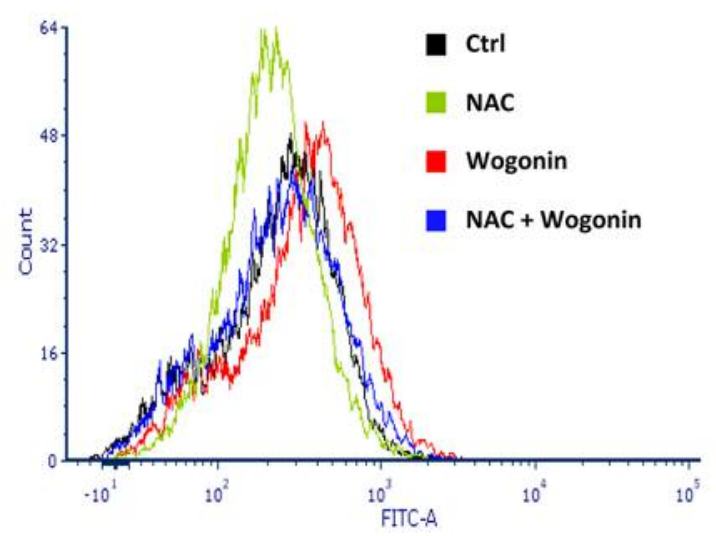

D

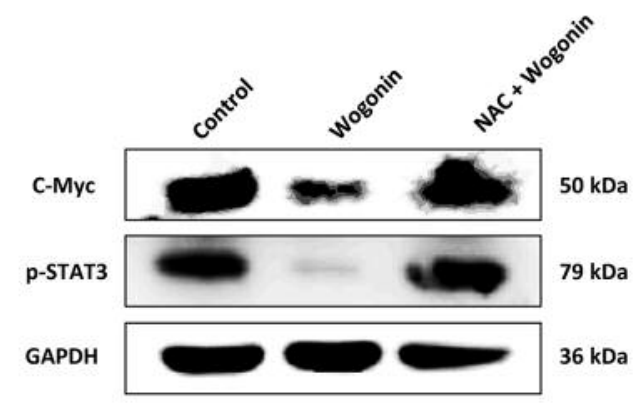

Figure 4. Inhibition of reactive oxygen species (ROS) produced by wogonin in CD133+ Cal72 cells by pre-treatment with N-acetylcysteine (NAC). A: Cell proliferation was increased by NAC pre-treatment. B: Flow cytometric assay showed the ROS level was reduced by NAC pre-treatment. C: Sphere-formation assay showed NAC blocked the effect of wogonin as a suppressor of self-renewal. D: Western blotting showed pre-treatment with NAC restored expression of myelocytomatosis (MYC) and phosphorylated signal transducer and activator of transcription 3 (pSTAT3). Significantly different from control cells (Ctrl) at $* p<0.05$ and $* * * p<0.001$.

as PRX1-6 according to their intracellular region. PRX5 in particular, located within mitochondria, can effectively remove ROS generated in the mitochondria (21). In the present study, we showed that wogonin down-regulated the expression of PRX5 on $\mathrm{CD}_{13} 3^{+} \mathrm{Cal} 72$ cells and induced ROS. The results indicate that PRX5 appears to be a key player in ROS production in osteosarcoma stem cells.

STAT3 is transcription factor that involved in growth and metastasis in several types of cancer cell $(22,23)$. STAT3 is highly expressed in osteosarcoma and may be a key molecular target for developing drugs for human osteosarcoma (24). Furthermore, some studies already showed that the inhibition of STAT3 led to ROS generation in human osteosarcoma cells (25). In addition, it has been reported that activation of ERK signaling is regulated by ROS and PRX5 knockdown up-regulated ERK activation related to activation of dynamin-related protein 1 (26). Our results suggest that wogonin down-regulates the expression of PRX5 and activates ERK signaling by increasing the ROS level.

It has been reported that MYC and OCT3/4, stem cellrelated genes, have been used to induce the differentiation of osteosarcoma stem cells (27). CD133, a CSC marker, plays a pivotal role in tumor growth, metastasis, tumorigenesis and relapse of cancer (7). It is expected that the reduction of stemness-related genes, especially of CD133, may be a key treatment method for the elimination of CSCs. In this study, we showed that the expression of stemness-related genes was reduced by wogonin treatment.

In conclusion, our study suggests that wogonin is cytotoxic to osteosarcoma cells via suppressing stemness by 
regulating ROS-related signaling. Although no in vivo study was performed here, our in vitro results provide evidence that wogonin may be a promising candidate for osteosarcoma therapy, increasing our understanding of the mechanisms associated with wogonin effects on ROS, especially with respect to its effects on stemness.

\section{Conflicts of Interest}

The Authors declare no conflicts of interest.

\section{Authors' Contributions}

Hyebin Koh and Hu-Nan Sun designed and performed all the experiments. Zhen Xing, Ren Liu, and Nisansala Chandimali performed the analysis of ROS and image analysis. Taeho Kwon, Jong-Hee Lee, Sun-Uk Kim performed the data analysis. Dong-Sun Lee supervised the study. All Authors read and approved the final article.

\section{Acknowledgements}

This research was supported by the Basic Science Research Program through the National Research Foundation of Korea (NRF) funded by the Ministry of Education (NRF-2016R1A6A1A03012862) and by the project for Cooperative Research Program for Agriculture Science and Technology Development (PJ01316701) Rural Development Administration, Republic of Korea.

\section{References}

1 Sakthikumar S, Elvers I, Kim J, Arendt ML, Thomas R, TurnerMaier J, Swofford R, Johnson J, Schumacher SE, Alfoldi J, Axelsson E, Couto CG, Kisseberth WC, Pettersson ME, Getz G, Meadows JRS, Modiano JF, Breen M, Kierczak M, Forsberg-Nilsson K, Marinescu VD and Lindblad-Toh K: Setd2 is recurrently mutated in whole-exome sequenced canine osteosarcoma. Cancer Res 78(13): 3421-3431, 2018. PMID: 29724721. DOI: 10.1158/0008-5472.CAN-17-3558

2 Abarrategi A, Tornin J, Martinez-Cruzado L, Hamilton A, Martinez-Campos E, Rodrigo JP, Gonzalez MV, Baldini N, Garcia-Castro J and Rodriguez R: Osteosarcoma: Cells-of-origin, cancer stem cells, and targeted therapies. Stem Cells Int 2016: 3631764, 2016. PMID: 27366153. DOI: 10.1155/2016/3631764

3 Kansara M, Teng MW, Smyth MJ and Thomas DM: Translational biology of osteosarcoma. Nat Rev Cancer 14(11): 722-735, 2014. PMID: 25319867. DOI: $10.1038 / \mathrm{nrc} 3838$

4 Ji Q, Xu X, Song Q, Xu Y, Tai Y, Goodman SB, Bi W, Xu M, Jiao S, Maloney WJ and Wang Y: $m i R-223-3 p$ inhibits human osteosarcoma metastasis and progression by directly targeting CDH6. Mol Ther 26(5): 1299-1312, 2018. PMID: 29628305. DOI: $10.1016 /$ j.ymthe 2018.03 .009

5 Ishiguro T, Ohata H, Sato A, Yamawaki K, Enomoto T and Okamoto K: Tumor-derived spheroids: Relevance to cancer stem cells and clinical applications. Cancer Sci 108(3): 283-289, 2017. PMID: 28064442. DOI: 10.1111/cas.13155

6 Shiozawa Y, Nie B, Pienta KJ, Morgan TM and Taichman RS: Cancer stem cells and their role in metastasis. Pharmacol Ther
138(2): 285-293, 2013. PMID: 23384596. DOI: 10.1016/ j.pharmthera.2013.01.014

7 Jang JW, Song Y, Kim SH, Kim J and Seo HR: Potential mechanisms of CD133 in cancer stem cells. Life Sci 18: 25-29, 2017. PMID: 28697984. DOI: 10.1016/j.lfs.2017.07.008

8 Huang K, Chen Y, Zhang R, Wu Y, Ma Y, Fang X and Shen S: Honokiol induces apoptosis and autophagy via the ROS/ERK1/2 signaling pathway in human osteosarcoma cells in vitro and in vivo. Cell Death Dis 9(2): 157, 2018. PMID: 29410403. DOI: 10.1038/s41419-017-0166-5

9 Son YW, Cheon MG, Kim Y and Jang HH: PRX2 links ROS homeostasis to stemness of cancer stem cells. Free Radic Biol Med 134: 260-267, 2019. PMID: 30611866. DOI: 10.1016/ j.freeradbiomed.2019.01.001

10 Kim SL, Choi HS, Kim JH, Jeong DK, Kim KS and Lee DS: Dihydrotanshinone-induced NOX5 activation inhibits breast cancer stem cell through the ROS/STAT3 signaling pathway. Oxid Med Cell Longev 2019: 9296439, 2019. PMID: 9296439. DOI: $10.1155 / 2019 / 9296439$

11 Khan NM, Ahmad I, Ansari MY and Haqqi TM: Wogonin, a natural flavonoid, intercalates with genomic DNA and exhibits protective effects in IL-1beta stimulated osteoarthritis chondrocytes. Chem Biol Interact 274: 13-23, 2017. PMID: 28688942. DOI: 10.1016/j.cbi.2017.06.025

12 Xing F, Sun C, Luo N, He Y, Chen M, Ding S, Liu C, Feng L and Cheng Z: Wogonin increases cisplatin sensitivity in ovarian cancer cells through inhibition of the phosphatidylinositol 3kinase (PI3K)/AKT pathway. Med Sci Monit 25: 6007-6014, 2019. PMID: 31402794. DOI: 10.12659/MSM.913829

13 Huynh DL, Kwon T, Zhang JJ, Sharma N, Gera M, Ghosh M, Kim N, Kim Cho S, Lee DS, Park YH and Jeong DK: Wogonin suppresses stem cell-like traits of CD133-positive osteosarcoma cell via inhibiting matrix metallopeptidase-9 expression. BMC Complement Altern Med 17(1): 304, 2017. PMID: 28606135. DOI: 10.1186/s12906-017-1788-y

14 Chandimali N, Sun HN, Kong LZ, Zhen X, Liu R, Kwon T, Kim TD and Lee DS: Shikonin-induced apoptosis of colon cancer cells is reduced by peroxiredoxin V expression. Anticancer Res 39(11): 6115-6123, 2019. PMID: 28688942. DOI:10.21873/anticanres.13819

15 Chandimali N, Jeong DK and Kwon T: Peroxiredoxin II regulates cancer stem cells and stemness-associated properties of cancers. Cancers 10(9): 305, 2018. PMID: 30177619. DOI: 10.3390/cancers 10090305

16 Kim MH, Seong JB, Huh JW, Bae YC, Lee HS and Lee DS: Peroxiredoxin 5 ameliorates obesity-induced non-alcoholic fatty liver disease through the regulation of oxidative stress and AMPactivated protein kinase signaling. Redox Biol 28: 101315, 2019. PMID: 31505325. DOI: 10.1016/j.redox.2019.101315

17 Tang T, Wang S, Cai T, Cheng Z, Qi S and Qi Z: Calenduloside $\mathrm{E}$ inhibits lipopolysaccharide-induced inflammatory response by inhibiting activation of ROS-mediated JAK1-STAT3 signaling pathway in Raw264.7 cells. Nan Fang Yi Ke Da Xue Xue Bao 39(8): 904-910, 2019 (in Chinese). PMID: 31511209. DOI: 10.12122/j.issn.1673-4254.2019.08.05

18 Xie C, Yi J, Lu J, Nie M, Huang M, Rong J, Zhu Z, Chen J, Zhou X, Li B, Chen H, Lu N and Shu X: $N$-Acetylcysteine reduces ROS-mediated oxidative DNA damage and PI3K/AKT pathway activation induced by Helicobacter pylori infection. Oxid Med Cell Longev 2018: 1874985, 2018. PMID: 29854076. DOI: $0.1155 / 2018 / 1874985$ 
19 Matsui WH: Cancer stem cell signaling pathways. Medicine 95(1 Suppl 1): S8-S19, 2016. PMID: 27611937. DOI: 10.1097/ MD.0000000000004765

20 Rhee SG, Woo HA, Kil IS and Bae SH: Peroxiredoxin functions as a peroxidase and a regulator and sensor of local peroxides. $\mathrm{J}$ Biol Chem 287(7): 4403-4410, 2012. PMID: 22147704. DOI: 10.1074/jbc.R111.283432

21 Kim MH, Park SJ, Kim JH, Seong JB, Kim KM, Woo HA and Lee DS: Peroxiredoxin 5 regulates adipogenesis-attenuating oxidative stress in obese mouse models induced by a high-fat diet. Free Radic Biol Med 123: 27-38, 2018. PMID: 29777756. DOI: $10.1016 /$ j.freeradbiomed.2018.05.061

22 Wang Z, Shen J, Sun W, Zhang T, Zuo D, Wang H, Wang G, Xu J, Yin F, Mao M, Zhou Z, Hua Y and Cai Z: Antitumor activity of raddeanin a is mediated by JUN amino-terminal kinase activation and signal transducer and activator of transcription 3 inhibition in human osteosarcoma. Cancer Sci 110(5): 17461759, 2019. PMID: 30907478. DOI: 10.1111/cas.14008

$23 \mathrm{Kim}$ JH, Choi HS, Kim SL and Lee DS: The PAK1-STAT3 signaling pathway activates IL-6 gene transcription and human breast cancer stem cell formation. Cancers 11(10): 1527, 2019. PMID: 31658701. DOI: 10.3390/cancers 11101527

24 Zhang T, Li J, Yin F, Lin B, Wang Z, Xu J, Wang H, Zuo D, Wang G, Hua Y and Cai Z: Toosendanin demonstrates promising antitumor efficacy in osteosarcoma by targeting STAT3. Oncogene 36(47): 6627-6639, 2017. PMID: 28783167. DOI: $10.1038 /$ onc. 2017.270
25 Cai N, Zhou W, Ye LL, Chen J, Liang QN, Chang G and Chen JJ: The STAT3 inhibitor pimozide impedes cell proliferation and induces ROS generation in human osteosarcoma by suppressing catalase expression. Am J Transl Res 9(8): 3853-3866, 2017. PMID: 28861175.

26 Kim B, Park J, Chang KT, Lee DS. Peroxiredoxin 5 prevents amyloid-beta oligomer-induced neuronal cell death by inhibiting ERK-DRP1-mediated mitochondrial fragmentation. Free Radic Biol Med. 90: 184-194, 2016. PMID: 26582373. DOI: 10.1016/ j.freeradbiomed.2015.11.015

27 Wang Y, Sun HJ, Li RG, Wang XM, Cheng ZQ and Lou N: Reprogramming factors induce proliferation and inhibit apoptosis of melanoma cells by changing the expression of particular genes. Mol Med Rep 19(2): 967-973, 2019. PMID: 30569122. DOI: $10.3892 / \mathrm{mmr} .2018 .9753$
Received January 9, 2020

Revised January 27, 2020

Accepted January 29, 2020 